\title{
“A GUERRA CIVIL É A MATRIZ DE TODAS AS LUTAS DE PODER": O DEBATE COM O MARXISMO NA ANALÍTICA DO PODER DE MICHEL FOUCAULT
}

\author{
Lorena de Paula Balbino ${ }^{1}$ \\ Universidade Federal de São Carlos (UFSCar) \\ (D) https://orcid.org/0000-0001-7178-8729 \\ E-mail: lorenabalbino_@hotmail.com
}

\section{RESUMO:}

Fazer a genealogia do poder nunca foi o propósito claro de Foucault. No entanto, a questão do poder foi tema recorrente em suas investigações a ponto de estudiosos do trabalho do filósofo sugerirem uma divisão e organização de seu trabalho a partir de três eixos teóricos. Dentro dessa perspectiva, a analítica do poder marcaria a trajetória filosófica de Foucault na década de 1970. De fato, até 1994, ano de publicação do conjunto de textos, entrevistas e conferências de Foucault no Dits et écrits, a questão da analítica do poder era majoritariamente conhecida a partir de livros como Surveiller et punir (1975) e Histoire de la sexualité I: la volonté de savoir (1976). Com o início da publicação dos cursos no Collège de France a partir de 1997 as interpretações a respeito da analítica do poder sofrem um alargamento. Mas é somente em 2015 que a totalidade dos cursos de Foucault no Collège de France foram publicados, abrindo um importante caminho para a investigação a respeito das primeiras reflexões a respeito do poder. No presente artigo procuramos mostrar como os primeiros passos da analítica do poder de Michel Foucault se dá a partir de um contexto gauchiste ainda configurado em termos de dinástica do saber. Nesse sentido, procuramos mostrar como o período da dinástica corresponde a um esboço teórico, tentativas primeiras de conceituação do poder, marcadamente desenvolvido em contraposição com o marxismo. Essa contraposição se dá sobretudo na recusa tanto do esquema marxista de infra-superestrutura, quanto do modelo contratualista (hobbesiano) de sociedade estatal.

PALAVRAS-CHAVE: Poder; Genealogia; Foucault; Marxismo.

\section{« CIVIL WAR IS THE MATRIX OF ALL STRUGGLES OF POWER » : THE DEBATE WITH MARXISM IN THE ANALYSIS OF MICHEL FOUCAULT'S POWER}

\begin{abstract}
:
Making the genealogy of power was never Foucault's clear intent. However, the power issue was always a recurring theme in his investigations, to the point of scholars suggesting a division and organization of his work as from three theoretical axis. Within this perspective, the analytic of power would mark Foucault's philosophical path in the 70's. Indeed, until 1994, the year of publication of a series of texts, interviews and conferences by Foucault on Dits et écrits, the issue of the analytic of power was mostly known from books like urveiller et punir (1975) and Histoire de la sexualité I: la volonté de savoir (1976). With the beginning of the publication of the classes in Collège de France from 1997 the reading towards the analytic of power might undergo an enlargement. But it isn't until 2015 that the entirety of Foucault's classes on Collège de France were published, opening an important path towards the investigation concerning the first reflections regarding power. It is our intention to show on this paper how the first steps of the analytic of power by Michel Foucault comes to life from a gauchiste context still set in the terms of a dynastic of knowledge. Accordingly, we try to show how the dynastic period matches a theoretical sketch, first attempts of formulation of the power concept, distinctively elaborated in contrast with marxism. This opposition occurs mainly in the refusal both of the Marxist infra-superstructure scheme and of the contractualist (Hobbesian) model of state society.
\end{abstract}

KEYWORDS: Power ; Genealogy ; Foucault ; Marxism.

${ }^{1}$ Doutoranda em Filosofia pela Universidade Federal de São Carlos (UFSCar), São Carlos - SP, Brasil. Bolsista/CAPES.

BALBINO, Lorena de Paula. "A guerra civil é a matriz de todas as lutas de poder": o debate com o marxismo na analítica do poder de Michel Foucault. Griot : Revista de Filosofia, Amargosa-BA, v.18, n.2, p.281-294, dezembro, 2018. 
O que é necessário para se entender as táticas de poder? Foucault inicia seu curso do ano de 1973 no Collège de France com a observação de que para se entender o funcionamento dos sistemas penais e as táticas penais que lhes são correlativas é necessário uma crítica sistemática das noções de exclusão e transgressão ${ }^{2}$. Como bem salientou Frédéric Gros, não se tratava naquele momento de recorrer a temas que estavam presentes em Histoire de la folie e, muito menos, de denunciar uma sociedade intolerante dentro de uma retórica da exclusão (GROS, 2010, p. 6). Por esse motivo, Foucault gostaria de ver naquele ano o sistema penal como um conjunto de estratégias, de táticas, muito mais do que um efeito políticoinstitucional em que a prisão funciona como uma "peça tática" em uma guerra social (GROS, 2010, p.7).

Nessa ocasião, as táticas penais são vistas por Foucault como "operações que encontram o seu lugar entre o poder e aquilo sobre o que se exerce o poder - são operações que se desenrolam inteiramente dentro da esfera do poder" (FOUCAULT, 2015, p. 12). Por conta dessa posição Foucault considera as táticas penais como objetos que podem servir como analisadores das relações de poder. $O$ termo "analisadores" (analyseurs) é enfatizado como crítica a um outro termo, a saber, o de "revelador" (révélateurs). Isso porque, para Foucault, não se trata de buscar nas táticas penais uma ideologia que estaria presente, porém de forma velada, nas relações de poder. As táticas penais funcionam como instrumentos que operacionalizam uma análise e, não como um instrumento que faria emergir dos discursos um significado ocultado ou dissimulado. Ou seja, não se deve procurar ver naquilo que se analisa um discurso escondido, que estaria a encobrir aquilo que seriam as condições "reais" de existência. Em segundo lugar, se é possível tomarmos as táticas penais como analisadores de relações de poder então o que deve ser observado por excelência são as relações em torno do poder ou contra ele.

O jogo mesmo dos conflitos e das lutas em torno do poder centram-se, segundo Foucault, ao redor da noção de guerra civil e, por isso mesmo, a guerra civil deve ser posta no lugar central do exame dos sistemas penais. Em um primeiro momento, Foucault parece querer reparar essa noção no interior de um discurso histórico-filosófico-político em que a guerra civil jamais foi tomada como um "ponto de partida" para as análises sobre o poder. Mais do que colocada à revelia de uma análise sobre o poder, a guerra civil foi mesmo encoberta e negada por uma tradição do pensamento político que se pode reconhecer em Hobbes e Rousseau.

Foucault caracteriza o discurso histórico-filosófico-político ao qual pretende se contrapor como um discurso marcado pela negação da guerra civil. $O$ fato de que a guerra civil nunca seja considerada como algo positivo da qual possa partir uma análise, ou mesmo de que essa guerra civil não existe, constitui o que Foucault chama de um dos primeiros axiomas do exercício do poder (FOUCAULT, 2015, p. 13).

A hipótese que Foucault procura sustentar é, ao contrário, a de que a guerra civil é "o estado permanente a partir do qual é possível e é preciso compreender diversas dessas táticas de luta" (FOUCAULT, 2015, p. 13). A retomada da noção por Foucault considera ainda que: “a guerra civil é a matriz de todas as lutas de poder, de todas as estratégias do poder e, por conseguinte, também a matriz geral de todas as lutas a propósito do, e contra o poder" (FOUCAULT, 2013, p. 15)3. A partir dessa hipótese geral Foucault indica que irá procurar

\footnotetext{
${ }^{2}$ É preciso observar que Foucault havia utilizado a noção de exclusão no curso do ano anterior Théories et institutions pénales. A noção de transgressão também é uma noção que já havia sido utilizada amplamente por Foucault. Cf. Préface à la transgression, In: FOUCAULT, 2001, p. 261-78.

${ }^{3}$ Nessa passagem, utilizamos o texto em francês pois preferimos aqui a tradução "todas as lutas de poder" ao invés de "todas as lutas pelo poder".
}

BALBINO, Lorena de Paula. "A guerra civil é a matriz de todas as lutas de poder": o debate com o marxismo na analítica do poder de Michel Foucault. Griot : Revista de Filosofia, Amargosa-BA, v.18, n.2, p.281-294, dezembro, 2018. 
mostrar o jogo das táticas do poder e da guerra civil permanente na sociedade do século XIX e, mais precisamente ainda, em um período que privilegia os anos de 1825 a $1848^{4}$ que, segundo Foucault, são os anos de instauração do grande sistema penal.

A fim de deixar claro de qual ideia de guerra civil se trata em sua hipótese de trabalho Foucault afirma estar em curso uma guerra social dos: "ricos contra os pobres, dos proprietários contra aqueles que não possuem nada, dos patrões contra os proletários" (FOUCAULT, 2015, p. 21). Além dessa consideração preliminar, o filósofo deixa claro um segundo elemento de sua análise, a saber, a consciência clara de que o discurso sobre as leis sociais é feito por aqueles a quem elas não são destinadas, ou seja, a lei penal é destinada a uma parcela da sociedade 5 , mas, ao mesmo tempo, ela é feita por outra. Somada a essas duas observações preliminares, as ideias de que essa sociedade do século XIX será marcada pela vigilância universal e um sistema de reclusão também serão consideradas na análise.

Nesse campo sobre o qual Foucault procura demarcar sua ideia de guerra civil há certa tradição da teoria política que indica uma comunicação direta e orgânica entre guerra civil e guerra de todos contra todos (FOUCAULT, 2015, p. 24). Essa tradição remete a Hobbes e a sua obra de maior expressão, O Leviatã, em que há uma equiparação entre guerra civil e guerra de todos contra todos. Desse modo, o curso de 1973 tentará mostrar as consequências e o contexto dessa equiparação (FOUCAULT, 2015, p. 25).

A guerra civil de Hobbes, nos diz Foucault, é da dimensão natural e universal dos homens e, por seu caráter natural, a guerra é essencial ao indivíduo. Sendo assim, o que poderá trazer ordem à sociedade civil é, para Hobbes, o aparecimento de um soberano: "A guerra de todos contra todos só cessa a partir do momento em que o soberano é efetivamente constituído por essa transferência do poder" (FOUCAULT, 2015, p. 27). Essa delimitação do elemento natural da guerra civil hobbesiana é importante para compreendermos a ideia que Foucault sustentará, de que a guerra civil não é da dimensão natural de relações entre indivíduos enquanto indivíduos. Para Foucault:

não há guerra civil que não seja confronto de elementos coletivos: parentes, clientelas, religiões, etnias, comunidades linguísticas, classes, etc. É sempre por meio de massas, por meio de elementos coletivos e plurais que a guerra civil nasce, se desenrola, e se exerce. [...] Ademais, a guerra civil não só põe em cena elementos coletivos como também os constitui (FOUCAULT, 2015, p. 27).

O caráter constituinte da guerra civil e, o fato de que ela é não somente o elemento que faz emergir novas coletividades, mas, também, é o elemento unificador desses grupos insurgentes, é o ponto chave da hipótese foucaultiana. O fato de que "a guerra civil é o processo através do qual e pelo qual se constituem diversas coletividades novas"

\footnotetext{
4 Foucault apontará um período muito próximo (1830-1848) em Surveiller et punir o desaparecimento dos suplícios (FOUCAULT, 2015a, p. 269).

${ }^{5}$ Seria ainda interessante observar que o caráter de despossessão sobre o qual Foucault entende o proletariado é também aquele que Rancière pontua em sua obra $O$ desentendimento. Rancière faz observar que o termo proletário vem do latim "proletarii" que significava uma parte da população que não era contada como fazendo parte da cidade. Essa parcela da população nada possuía e por conta de sua despossessão não eram considerados cidadãos. Segundo Rancière: "A massa dos homens sem propriedade identifica-se à comunidade em nome do dano que não cessam de lhe causar aqueles cuja qualidade ou propriedade têm por efeito natural relançá-la na inexistência daqueles que não tomam 'parte em nada'. É em nome do dano que lhe é causado pelas outras partes que o povo se identifica com o todo da comunidade. Quem não tem parcela - os pobres da Antiguidade, o terceiro estado ou o proletariado moderno - não pode mesmo ter outra parcela a não ser nada ou tudo. Mas é também mediante a existência dessa parcela dos sem-parcela, desse nada que é tudo, que a comunidade existe enquanto comunidade política, ou seja, enquanto dividida por um litígio fundamental, por um litígio que afeta a contagem de suas partes antes mesmo de afetar seus “direitos"”. Cf. RANCIÈRE, J. O desentendimento. São Paulo: editora 34, 1995. p. 24.
}

BALBINO, Lorena de Paula. “A guerra civil é a matriz de todas as lutas de poder”: o debate com o marxismo na analítica do poder de Michel Foucault. Griot : Revista de Filosofia, Amargosa - BA, v.18, n.2, p.281-294, dezembro, 2018. 
(FOUCAULT, 2015, p. 27), tornou possível, segundo Foucault, que através dela um campesinato pudesse se constituir enquanto comunidade ideológica, de interesses e classe social, adquirindo uma unidade. Ainda outros exemplos são elencados como as revoltas em geral, revoltas por salários e sedições políticas que, pelo próprio processo da guerra civil, ganharam coesão e deram força unitária e coletiva a esse povo que será um dos personagens da Revolução Francesa (FOUCAULT, 2015, p. 27-28). Ou seja, segundo Foucault, a guerra civil deve ser vista como um processo coletivo que faz emergir novas coletividades, portanto, nunca algo que dissolveria o coletivo da vida dos indivíduos.

O esquema da guerra civil é ainda operacional na obra publicada em 1975, Surveiller et punir, e é acompanhado de um vocabulário que permite pensar a política "como continuação da guerra". Foucault escreve nessa ocasião que:

Se há uma série política-guerra que passa pela estratégia, há uma série exércitopolítica que passa pela tática. É a estratégia que permite compreender a guerra como uma maneira de conduzir a política entre os Estados; é a tática que permite compreender o exército como um princípio para manter a ausência de guerra na sociedade civil (FOUCAULT, 2015a, p. 442).

Ainda na mesma obra, Foucault deixa claro logo de início de que modo se deverá tratar a "microfísica do poder" posta em jogo entre as instituições e os aparelhos estatais no exercício do assujeitamento dos corpos. Assim, o estudo dessa microfísica não deverá conceber o poder como uma propriedade, mas como uma estratégia em que se decifre uma rede de relações sempre tensas na qual deverá ser analisado sob o "modelo da batalha perpétua de preferência ao do contrato que opera uma cessão ou a conquista que se apodera de um domínio" (FOUCAULT, 2015a, p. 287).

Era já a guerra que aparecia na análise de Foucault do curso anterior, a saber, Théories et institutions pénales, pois era a guerra que se repetia, no teatro do poder, de dominação em dominação. Foucault faz notar que as revoltas frumentárias do século XVIII obedeciam a um esquema constante de apropriação de ritos do poder. $O$ que o faz afirmar que "um movimento de revolta, portanto, não consiste tanto em destruir os elementos do poder quanto em apoderar-se deles e colocá-los em funcionamento" (FOUCAULT, 2015, p. 29). Nesse sentido, a guerra civil, em casos nos quais ela se desenrola essencialmente como coletivo, sem uma centralização única, ela agiria de modo a efetivar um mito do poder. Tal é o caso da revolta dos $\mathrm{Nu}$-pieds, estudado anteriormente, e do movimento luddista que, sobre um poder vacante, criaram um chefe mítico (Jean Nu-pieds e Ned Ludd) que deu coesão ao movimento.

A teoria política da qual nos fala Foucault teria ainda, ao negar e encobrir a guerra civil no seio da sociedade, feito com que o poder aparecesse como algo exterior à guerra civil. A hipótese de que a guerra civil é a matriz de todas as lutas de poder sustenta, ao contrário, que a guerra civil só se desenrola no interior de um poder já constituído para manter, conquistar, confiscar ou transformar essa configuração do poder. Portanto, a guerra civil não é uma "antítese" do poder: "Não há guerra civil sem trabalho de poder, trabalho sobre o poder" (FOUCAULT, 2013, p. 33). Assim, o plano da guerra civil deverá ser visto na análise que se segue como o campo sobre o qual o poder se faz sempre presente. Pois, para Foucault, o exercício:

${ }^{6}$ Nessa passagem não segui a tradução, preferindo "sobre o poder" a "com o poder" para "sur le pouvoir".

BALBINO, Lorena de Paula. "A guerra civil é a matriz de todas as lutas de poder": o debate com o marxismo na analítica do poder de Michel Foucault. Griot : Revista de Filosofia, Amargosa-BA, v.18, n.2, p.281-294, dezembro, 2018. 
podem ser distinguidas, essas alianças devem ser analisáveis em termos de guerra civil (FOUCAULT, 2015, p. 30-31).

Logo após escrever que a guerra civil é travada em torno do poder, Foucault indica em suas anotações do curso que dois problemas deverão ser "deixados de lado" nesse primeiro instante, a saber, o problema do par "poder/Estado" e o problema do par "guerra civil/l[uta de] classes" (FOUCAULT, 2015, p. 31). É possível vermos aí uma menção velada a outro "teórico" da guerra civil.

Esse outro "teórico" da guerra civil" que Foucault não menciona diretamente nas primeiras aulas do curso, é Marx ${ }^{7}$ É possível que a alusão não explicita a Marx tenha sido "deixada de lado" pelo fato de o trabalho do filósofo alemão não corresponder a uma teoria da guerra civil que seja uma antítese do poder. Pelo contrário, segundo Sandro Chignola, em Marx:

O esquema teórico-político da modernidade jurídica se encontra assim invertido. Segundo o contratualismo moderno, a sociedade é tornada possível pelo poder que a organiza e a captura em um sistema de poderes secundários, hierarquicamente subordinados, posta em movimento e autorizadas pela unidade do soberano. Em Marx, ao contrário, é a existência de formas de exercício do poder locais e difusos em todo o espaço social - a propriedade privada, a escravidão, a usina, o exército -, que antecipa e determina a constituição dos aparelhos de Estado (CHIGNOLA, 2015, p. 47).

A um primeiro olhar, a ideia de que "a guerra civil é a matriz das lutas de poder" sobre o pano de fundo do par "guerra civil-luta de classes" parece mesmo inverter a tese de Marx, presente no Manifesto comunista, de que "A história de todas as sociedades até hoje existentes é a história das lutas de classes" (MARX, 2010, p. 40). No Manifesto comunista Marx coloca resumidamente o propósito de sua exposição:

Esboçando em linhas gerais as fases do desenvolvimento proletário, descrevemos a história da guerra civil mais ou menos oculta na sociedade existente, até a hora em que essa guerra explode numa revolução aberta e o proletariado estabelece sua dominação pela derrubada violenta da burguesia (MARX, 2010, p. 50).

E ainda em seu escrito da mesma época, Marx descreve o que via na França:

A fraternité, a fraternidade das classes antagônicas, em que uma explora a outra, a fraternité, proclamada em fevereiro, inscrita com grandes letras nas fachadas de Paris, em cada prisão, em cada caserna, tem como expressão verdadeira, genuína e prosaica a guerra civil, a guerra civil na sua feição mais terrível, a guerra do trabalho contra o capital (MARX, 2012, p. 63).

A guerra está presente no discurso de Marx como elemento de uma força maior que é a violência, pois, como afirma no livro I do Capital: "Na história real, como se sabe, o papel principal é desempenhado pela conquista, a subjugação, o assassínio para roubar, em suma, a violência" (MARX, 2013, p. 786). Na própria gênese do capital, ou seja, no processo de

\footnotetext{
${ }^{7}$ Christian Laval sustenta que Marx foi um teórico da guerra: "Mas é sem dúvida também para afirmar que Marx, por conta do interesse que sempre teve pela guerra e a luta, não foi somente o teórico do processo de autovalorização do capital, mas também um pensador senão tão secreto, em todo caso pouco comentado, do papel da guerra na história das sociedades" (LAVAL, 2015, p. 41).
}

BALBINO, Lorena de Paula. “A guerra civil é a matriz de todas as lutas de poder”: o debate com o marxismo na analítica do poder de Michel Foucault. Griot : Revista de Filosofia, Amargosa-BA, v.18, n.2, p.281-294, dezembro, 2018. 
acumulação primitiva, Marx descreve uma espécie de violência fundadora do capitalismo ${ }^{8}$ que é a expropriação violenta das massas populares das terras onde viviam ${ }^{9}$.

$O$ fato de Marx ver na luta de classes a guerra civil, ou ainda, o fato de a guerra civil ser a expressão maior da luta de classes não exime Marx de, em certo sentido, estar de acordo com Hobbes em sua compreensão da vida social como uma guerra civil iminente. Apesar disso, o que está em questão aqui não são as condições de formação da sociedade, mas, a emergência de um antagonismo que opõe uma classe de proprietários a uma classe de despossuídos. Sendo assim, a guerra civil em Marx é descrita em seu discurso como "luta de classes".

Ora, não se está falando de algo muito diferente no curso de 1973 quando Foucault afirma que a guerra civil da qual está tratando é aquela dos "proprietários contra aqueles que não possuem nada". E, se o poder não é o que suprime a guerra civil, mas, ao contrário, aquilo que a enceta e a movimenta, então a questão que devemos também colocar é se o poder, no plano da guerra civil, pode ser interpretado como uma espécie de luta de classes. $\mathrm{Ou}$, nas palavras de Foucault:

eu diria, no limite, o poder é a luta de classes, ou seja, o conjunto das relações de força, isto é, as relações forçosamente desiguais, mas igualmente cambiantes, que pode haver em um corpo social e que são as atualizações, os dramas cotidianos da luta de classes ${ }^{10}$

Mas, como veremos, não se trata aqui de uma oposição a Marx. A afirmação de Foucault de que a guerra civil deve ser vista como a matriz de todas as lutas de poder desloca um problema clássico entre os marxistas, a saber, qual é o problema do Estado em uma análise do poder. Desse modo, a análise de Foucault deve ser vista como a negação da premissa althusseriana, exposta no artigo Ideologia e aparelhos ideológicos de Estado, de que: “Toda a luta política de classes gira em torno do Estado: entendamos, em torno da detenção, ou seja, da tomada ou da conservação do poder de Estado, por uma certa classe, ou por uma aliança de classes ou de frações de classes" (ALTHUSSER, 1995, p. 279). Como fica claro em sua hipótese sobre a guerra civil e a crítica que faz ao contratualismo, Foucault recusa ver no Estado a fonte ou a origem das relações de poder. Assim é que o problema da guerra civil será muito mais operacional para entender o poder e as relações que se desencadeiam em torno dele.

A partir então desse pano de fundo, Foucault irá analisar como a reclusão se impôs e se generalizou como tática punitiva no século XVIII. Desse modo, uma nova figura vem para o centro da cena, a saber, a figura do criminoso-inimigo social. $O$ criminoso é o inimigo social que, ao cometer um crime, reativa a guerra de todos contra todos, ou ainda de um contra todos ${ }^{11}$ : "a punição, portanto, instala-se a partir de uma definição do criminoso como

\footnotetext{
$8 \mathrm{Na}$ apresentação da edição francesa do livro I de O Capital, Althusser afirma que a acumulação primitiva se realizou graças a violência e, que foi a partir de seus meios que o capitalismo pôde nascer e se desenvolver nas sociedades ocidentais: "Esses meios são a mais brutal violência, o roubo e os massacres que abriram para o capitalismo sua via régia na história humana. Este último capítulo contém riquezas prodigiosas que não foram ainda exploradas, em especial a tese (que devemos desenvolver) de que o capitalismo nunca deixou de empregar, e continua a empregar em pleno século XX, nas 'margens' de sua existência metropolitana, isto é, nos países coloniais e ex-coloniais, os meios da mais brutal violência" (ALTHUSSER apud MARX, 2013, p. 49).

${ }^{9}$ Cf. MARX, 2013, p. 790, 792.

10 FOUGAULT, 1977, p. 7.

11 Faz-se necessário observar que a emergência do criminoso como inimigo social e a compreensão de que o crime é um ataque à sociedade se contrapõe a duas outras compreensões, a saber, do crime como prejuízo e do crime como atentado a soberania (crime de estado). A compreensão do criminoso como inimigo social pode ser entendida nos moldes da teoria do contrato social e, mais especificamente, no contrato social de Rousseau: "Todo malfeitor que ataca o direito social torna-se,
}

BALBINO, Lorena de Paula. "A guerra civil é a matriz de todas as lutas de poder": o debate com o marxismo na analítica do poder de Michel Foucault. Griot : Revista de Filosofia, Amargosa - BA, v.18, n.2, p.281-294, dezembro, 2018. 
aquele que guerreia contra a sociedade" (FOUCAULT, 2015, p. 32). Se, portanto, o criminoso é um inimigo social, sua punição já não deve mais ser a reparação de um dano, mas uma medida de proteção social.

Embora os teóricos do século XVIII baseiem seu discurso teórico-jurídico na definição do crime como hostilidade social esse tipo de discurso tem sua derivação institucional já desde a Idade Média. A partir da centralização do poder monárquico, como Foucault pôde mostrar no curso do ano anterior, parte do controle dos litígios judiciários passam a fazer parte do poder monárquico. Com isso, a ação pública movida por um procurador ou um advogado do rei, transforma o crime em um processo movido pelas autoridades, substituindo a ação privada de vingança ou reparação que vigorava no sistema germânico. Assim, o soberano coloca-se diante do criminoso e, em nome da ordem e da paz, o condena por ter-se posto num estado de guerra "selvagem" com um indivíduo (FOUCAULT, 2015, p. 32).

Além disso, há para Foucault um elemento que é o comutador desses dois discursos do criminoso como inimigo social e como inimigo público. Esse elemento comutador é o júri. O júri, tal como em funcionamento no século XIX, é a instituição que faz com que a própria sociedade possa julgar alguém que se colocou em conflito com ela:

Essa espécie de conector que constitui o criminoso como inimigo social é na realidade um instrumento por meio do qual a classe que está no poder transfere para a sociedade, na forma de júri, ou para a consciência social, por todas essas interdições epistêmicas, a função de rejeitar o criminoso (FOUCAULT, 2015, p. 34).

Para empreender esse exame, Foucault irá mobilizar todo um aparato crítico que vinculará economia política e genealogia da moral (HARCOURT apud FOUCAULT, 2015, p. 244). As análises que se seguirão irão constituir uma espécie de genealogia do proletariado em que a passagem da transformação da força de trabalho em força produtiva será fundamental à compreensão da instauração do sistema penal. Nesse sentido, veremos a constituição de uma positividade do capitalismo, o que significa, em outras palavras, que o capitalismo produzirá não só valor, mas também, a produção de um saber e de uma nova economia do tempo e da vida. Assim é que, a produção da força de trabalho e o surgimento do criminoso como inimigo social irá produzir um conjunto de práticas que terão por objetivo a sequestração e transformação do tempo da vida em tempo do trabalho. Será nesse sentido que Foucault fará uma correspondência entre a forma-prisão da penalidade e a forma-salário do trabalho.

O aparecimento do criminoso como inimigo social não é do nível de uma formação ideológica. Segundo Foucault, trata-se de algo que ocorre em outro nível e que será efetivamente a constituição:

de um estado de hostilidade entre os criminosos e a totalidade do corpo político; a designação de uma frente de guerra; toda uma empreitada de segregação por meio do qual os criminosos, por um lado, e a sociedade, por outro, vão encontrar-se frente a frente (FOUCAULT, 2015, p. 58).

Foucault identifica as primeiras manifestações do criminoso como inimigo social no que ele chama de "análise em termos de economia política" (FOUCAULT, 2015, p. 47). A

por seus malfeitos, rebelde e traidor da pátria, deixa de ser seu membro violando suas leis e até mesmo trava guerra contra ela. Então a conservação do Estado é incompatível com a dele, é preciso que um dos dois pereça, e o culpado, quando levado à morte, o é menos como cidadão do que como inimigo" (O contrato social: princípios do direito político, São Paulo: Martins Fontes, 2006).

BALBINO, Lorena de Paula. "A guerra civil é a matriz de todas as lutas de poder": o debate com o marxismo na analítica do poder de Michel Foucault. Griot : Revista de Filosofia, Amargosa - BA, v.18, n.2, p.281-294, dezembro, 2018. 
análise da delinquência em relação aos processos de produção aparecerá na segunda metade do século XVIII, segundo Foucault, entre os fisiocratas ${ }^{12}$. No discurso fisiocrático: "é a própria posição do delinquente relativamente à produção que o define como inimigo público" (FOUCAULT, 2015, p. 43). Por esse motivo a delinquência será analisada segundo suas consequências econômicas. Como exemplo maior, Foucault irá buscar na obra "Mémoire sur les vagabonds et sur les mendiants" de Le Trosne as consequências econômicas da vagabundagem. Assim, podemos ler nesse fisiocrata do século XVIII que o ato de vagar sem rumo, ou seja, o fato de o cidadão não ter um elo comunitário fixo, provoca uma diminuição da mão de obra com consequente aumento dos salários, a redução da produção e, além disso, a consequência de que esses que vagam sem rumo escapam ao recolhimento de impostos. Portanto, aquele que é errante: "é alguém que perturba a produção, e não só um consumidor estéril. Logo, ele se encontra numa posição de hostilidade constitutiva em relação aos mecanismos normais de produção" (FOUCAULT, 2015, p. 44).

Resumindo o que constitui o crime do vagabundo para os fisiocratas, Foucault reconhece uma identidade primordial e fundamental entre a vacância e a recusa de trabalho. Pois, para os fisiocratas, não há relação entre falta de trabalho e mendicância, uma vez que não é concebida a hipótese de que haja falta de trabalho. Na teoria fisiocrática, segundo Foucault, "sempre há trabalho suficiente para cada um, mesmo que não haja sustento suficiente para todos" (FOUCAULT, 2015, p. 45). E se os vagabundos se multiplicam pela sociedade é porque, por meio da violência, eles roubam, ameaçam, incendeiam e matam, subsistindo por meio do estabelecimento de uma relação de poder selvagem com a sociedade (FOUCAULT, 2015, p. 45). Ora, o que a teoria fisiocrática promove com a relação entre recusa a trabalho e violência não é senão uma culpabilização e moralização da população inativa. Nesse sentido, o discurso de Le Trosne encarna para Foucault uma:

[espécie] de devaneio furioso, de antecipação fictícia, aquilo que, por outros meios e
por ardis também sutis, o poder em ação na sociedade capitalista fez para conseguir
fixar no trabalho todos aqueles que tinham tendência a mover-se. Le Trosne sonhou
com essa grande reclusão no local de trabalho; viu essa espécie de grande massacre
no qual seria possível matar toda e qualquer pessoa que se recusasse
fundamentalmente à fixação, cena de caçada feudal, mas já capitalista
(FOUCAULT, 2015, p. 48).

Mas esses homens que se recusam a trabalhar, que não pagam impostos, que oneram a sociedade com seus filhos legítimos são também os monges itinerantes, os nobres e os agentes fiscais. $\mathrm{Ou}$ seja, a própria sociedade feudal da qual a burguesia queria se livrar. $\mathrm{O}$ discurso de Le Trosne é significativo pois coloca em evidência duas formas pelas quais alguém poderia estar em guerra com a sociedade. Estar em guerra com a sociedade é exercer um poder que crie um obstáculo à produção ou simplesmente recusar-se a produzir. Na superfície desse discurso o que aparece é um novo personagem, personagem que não é mais simplesmente o soberano, mas, a sociedade enquanto um sistema de relações entre indivíduos que possibilitam a produção. É por isso que o discurso de Le Trosne antecipa o discurso capitalista, pois nesse discurso, estar em guerra com a sociedade é ser contrário a maximização da produção.

\footnotetext{
12 São frequentes as análises de Foucault a respeito do pensamento fisiocrático. A esse respeito conferir o capítulo "A formação do valor" de As palavras e as coisas. Em História da loucura a população como fator de riqueza no fisiocratismo. Em Segurança, território, população as ideias de dispositivo de segurança e, por fim, as análises do neoliberalismo em Nascimento da biopolitica.
}

BALBINO, Lorena de Paula. “A guerra civil é a matriz de todas as lutas de poder”: o debate com o marxismo na analítica do poder de Michel Foucault. Griot : Revista de Filosofia, Amargosa-BA, v.18, n.2, p.281-294, dezembro, 2018. 
Foucault aponta que seria ainda possível analisar o efeito teórico-político do discurso do criminoso como inimigo social. Essa análise deveria levar em conta o contexto das discussões políticas, oposições e batalhas oratórias a respeito. Nessa ocasião o filósofo francês faz sua única menção a Marx no interior do curso para indicar que os escritos do filósofo alemão referente a lei sobre o furto da madeira deveriam ser levados em conta quando se fizesse uma análise de tal tipo. Os escritos de Marx sobre os delitos florestais tratavam diretamente das relações entre o parcelamento da propriedade fundiária e as condições de existência dos camponeses. É possível acompanhar na sequência dos cinco artigos de Marx o debate jurídico-político que, no século XIX, condenava as classes pobres a criminalidade ${ }^{13}$.

No momento mesmo em que vemos formular-se o princípio do criminoso como inimigo social vê-se implantar a reclusão massiva como sistema punitivo. No entanto, não se deve depreender disso que, os princípios teóricos que começavam a esboçar variantes formas de punição conduziram o sistema penal a prisão propriamente dita. Ambos os fenômenos se entrecruzam:

Essa oposição, no nível dos discursos, entre, de um lado, os tipos de saber autorizados pela prática do direito e, de outro, pela prática da reclusão apenas reproduz o jogo que se encontra no nível das instituições: a perpétua tentativa do sistema penitenciário de escapar à penetração do jurídico e da lei, e o esforço do sistema judiciário para controlar o sistema penitenciário que lhe é heterogêneo (FOUCAULT, 2015, p. 61).

Acontece que a prisão que é "um sistema punitivo abstrato, monótono e rígido [...] se impôs não só nos fatos [...] mas no próprio interior do discurso" (FOUCAULT, 2015, p. 65). Ou seja, no momento em que as variáveis dos modelos teóricos do criminoso como inimigo social estavam sendo elaborados, tudo já estava definido. Desse modo, o denominador comum que será capaz de substituir todas as variáveis previstas nos modelos teóricos será o tempo. O que interessa a Foucault nesse momento é mostrar como e sob quais formas a introdução do tempo como forma de punição foi tornado possível.

A introdução do tempo no sistema penal e, ao mesmo tempo, no sistema capitalista irá submeter a vida a uma disciplinarização que tem por objetivo "sujeitar o tempo da existência dos homens a esse sistema temporal do ciclo da produção" (FOUCAULT, 2015, p. 194). Essa sujeição da vida ao tempo ${ }^{14}$ se desenvolverá de forma a penetrar tanto no poder

\footnotetext{
${ }^{13}$ Diz Marx sobre o debate a respeito da aprovação de um parágrafo que deveria legislar não só sobre a exploração da madeira, mas, também, sobre a subtração da madeira caída ou recolhimento da madeira seca: "Se, por um lado, o parágrafo for aprovado, será necessário cortar uma massa de pessoas sem intenção criminosa de árvore verdejante da moralidade e lança-la qual madeira seca no inferno da criminalidade, da infâmia e da miséria. Se, por outro lado, o parágrafo for rejeitado, haverá a possibilidade de que algumas árvores novas sofram maus-tratos, e alegar isso é quase desnecessário! Os ídolos de madeira obtêm a vitória e as vítimas humanas são abatidas!". O argumento de Marx em favor da classe pobre era o recurso a um direito consuetudinário: "Reivindicamos para a pobreza o direito consuetudinário, mais precisamente um direito consuetudinário da pobreza em todos os países. Vamos ainda além e afirmamos que, por sua natureza, o direito consuetudinário só pode ser o direito dessa massa mais baixa, sem posses e elementar". (Marx, K. 2017, p. 80 e 84).

${ }^{14}$ Foucault faz referência no curso de 1973 a Edward P. Thompson que, segundo Daniel Defert nas notas do curso afirma um profundo conhecimento de Foucault do trabalho do historiador inglês. Thompson, em artigo de 1967, "Tempo, disciplina de trabalho e capitalismo industrial", coloca em questão até que ponto uma mudança na notação do tempo influenciou a sociedade industrial e acarretou uma reestruturação na disciplina de trabalho. Ele afirma que entre os anos de 1300 e 1650 houveram importantes mudanças na percepção do tempo na Europa ocidental. Uma dessas mudanças significativas se refere ao fato de que o tempo se torna moeda, desse modo, ninguém mais passa o tempo, gasta-o. Segundo Thompson: "Aqueles que são contratados experienciam uma distinção entre o tempo do empregador e o seu "próprio" tempo. E o empregador deve usar o tempo de sua mão-de-obra e cuidar para que não seja desperdiçado: o que predomina não é a tarefa, mas o valor do tempo quando reduzido a dinheiro" (THOMPSON, 2010, p. 272). Thompson concluiu que a administração mais rigorosa da força de trabalho não se dava segundo uma questão de novas técnicas de medição do tempo, mas sim, devido a uma "percepção mais aguçada" dos empregadores capitalistas quanto ao uso regrado do tempo.
}

BALBINO, Lorena de Paula. "A guerra civil é a matriz de todas as lutas de poder": o debate com o marxismo na analítica do poder de Michel Foucault. Griot : Revista de Filosofia, Amargosa-BA, v.18, n.2, p.281-294, dezembro, 2018. 
capitalista, como no sistema penal. Foucault enxergará nisso duas formas historicamente gêmeas: a forma-prisão e a forma-salário.

O tempo é a moeda de pagamento tanto na prisão quanto na produção. Se é um salário que é pago pelo tempo durante o qual a força de trabalho de alguém pode ser comprada, a pena de reclusão será contabilizada em quantidade de tempo de liberdade. Ou seja, uma infração não responderá mais à lógica da reparação, do ajustamento, da marcação no corpo ou da confiscação de bens, mas sim, ao preço de certo tempo de liberdade que é propriamente o tempo por viver. Não que a forma-salário tenha sido transferida para a forma-prisão, mas, estudar porque salário e prisão aproximam-se e comunicam-se através de um sistema de trocas e medidas de extração real do tempo é um problema maior de um certo aparato de poder.

Então, o que podemos ver se esboçar mais claramente é a questão do porquê de uma análise em termos de repressão, exclusão, transgressão, não permitir fazer ver as funções produtivas da penalidade. No ano de 1972, a propósito de sua visita à prisão de Attica nos Estados Unidos, Foucault concede uma entrevista em que esclarece sob qual perspectiva ele coloca o problema da prisão:

A prisão é uma organização demasiado complexa para a reduzirmos a funções
puramente negativas de exclusão; seu custo, sua importância, o cuidado que
tomamos para a administrar, as justificações que tentamos dar, tudo isso parece
indicar que ela possui funções positivas. O problema torna-se então o de descobrir
qual papel a sociedade capitalista faz seu sistema penal desempenhar, que objetivo é
buscado, que efeitos produzem todos esses procedimentos de castigo e de exclusão.
Que lugar eles ocupam no processo econômico, que importância tem no exercício e
na manutenção do poder; que papel desempenham no conflito de classes
(FOUCAULT, 2001, p. 1396).

O assujeitamento do tempo da vida dos homens ao tempo da produção e o ajustamento dos corpos trabalhadores a uma disciplina de trabalho se realizará como um jogo de forças que passará por uma disciplinarização e uma moralização da classe trabalhadora. O tempo, como instrumento do poder capitalista, deverá organizar por inteiro a vida do operário na fábrica, bem como a distribuição e o cálculo desse tempo no salário e, de modo algum, deixar escapar de seu controle o tempo do lazer da vida operária. Portanto, a moralização da classe trabalhadora será vinculada a um bom uso do tempo, tanto o tempo de trabalho, como o tempo da ociosidade, que não deverá ser gasto com atividades de "desvio moral".

A interpenetração da forma-prisão e da forma-salário, apontam para o caráter produtivo que o poder tem na sociedade moderna. A produtividade do poder terá aspectos e práticas diferentes que atravessam os corpos e os tornam uteis, que produzem discursos e saberes, e que procura conduzir condutas a partir de objetivos de eficácia. A hipótese de uma produtividade do poder pode ser encontrada, segundo Foucault afirma, no Marx de $O$ capital $^{15}$. De fato, é possível encontrar essa produtividade do poder no Capital de Marx quando esse descreve a transformação do corpo em força de trabalho e em força produtiva. Segundo Marx, os métodos para aumentar a força produtiva de trabalho transformam o tempo de vida em tempo de trabalho ${ }^{16}$. Marx analisa ainda como a redução da jornada de

\footnotetext{
15 Cf. FOUCAULT, 2001a, p. 1005. "Como poderíamos tentar analisar o poder em seus mecanismos positivos? Me parece que podemos encontrar em um certo número de textos, os elementos fundamentais para uma análise desse tipo. [...] podemos evidentemente os encontrar também em Marx, essencialmente no livro II do Capital".

${ }^{16}$ Cf. Marx, K. 2013, p. 720.
}

BALBINO, Lorena de Paula. “A guerra civil é a matriz de todas as lutas de poder”: o debate com o marxismo na analítica do poder de Michel Foucault. Griot : Revista de Filosofia, Amargosa-BA, v.18, n.2, p.281-294, dezembro, 2018. 
trabalho e a criação de um tempo livre é ainda um meio para transformar esse tempo em um tempo disponível a valorização do capital ${ }^{17}$.

Já em Marx a regulação da jornada de trabalho teria um caráter belicoso. Isso é exposto pelo filósofo alemão no capítulo oito do livro 1 do Capital, em que observa que "A criação de uma jornada normal de trabalho é, por isso, o produto de uma longa e mais ou menos oculta guerra civil entre as classes capitalista e trabalhadora"18. É, especialmente, sobre esse aspecto que Foucault, segundo Christian Laval, alarga o diagnóstico de Marx. Segundo Christian Laval:

\begin{abstract}
A formação do proletariado necessitou de uma guerra social de grande amplitude contra todos os tipos de condutas que escapavam a fixação da mão de obra e impediam a mobilização de uma população laboriosa. Era preciso em suma se ocupar da "acumulação dos homens" tanto quanto da acumulação do capital, era preciso organizar essa multiplicidade humana, a compor, a tornar útil socialmente, politicamente, economicamente (LAVAL, 2015, p. 35) ${ }^{19}$.
\end{abstract}

Nesse sentido, a constituição de uma mão de obra disciplinada que tinha sobretudo o corpo como lugar de investimento de técnicas disciplinares é colocado no centro dessa guerra civil sob o qual Foucault procura analisar a sociedade. A "invenção" dessas técnicas não deve, nos diz Foucault em Surveiller et Punir ${ }^{20}$, ser entendidas como uma descoberta súbita. Elas têm sua origem em uma multiplicidade de processos e em localizações esparsas. É por isso que sua análise compreende observar as diversas fórmulas da disciplina nas escolas, nos quarteis, nas fábricas e até na prisão. Em todas essas instituições a organização do tempo é esquadrinhado para que não haja, em um só momento, um desperdício ou uma má utilização:

O tempo medido e pago deve ser também um tempo sem impureza nem defeito, um tempo de boa qualidade, e durante todo o seu transcurso o corpo deve ficar aplicado a seu exercício. A exatidão e a aplicação são, com a regularidade, as virtudes fundamentais do tempo disciplinar (FOUCAULT, 2015a, p. 421).

Essa multiplicidade de instituições, que teve seu recrudescimento no século XIX, fez com que, durante toda a vida as pessoas mantivessem um elo com essas instituições que não as representavam exatamente e que, muito menos, as constituíam como grupo. Diz-nos Foucault que:

percebe-se que naquele momento emergiram 'corpos' absolutamente novos no espaço social, corpos diferentes daqueles que vinham à mente outrora quando se falava de corporações e grêmios. Não eram corpos sociais, ou seja, corpos de pertencimento, que apareciam com instituições como creches, caixas econômicas ou previdenciárias e prisões. Tampouco eram corpos que funcionassem ao modo da máquina, ou seja, corpos produtores, ainda que houvesse elos entre o

\footnotetext{
${ }_{17}$ Cf. Marx, K. 2013. "Daí o paradoxo econômico de que o meio mais poderoso para encurtar a jornada de trabalho se converte no meio infalível de transformar todo o tempo de vida do trabalhador e de sua família em tempo de trabalho disponível para a valorização do capital" (p. 480). "Na sociedade capitalista, produz-se tempo livre para uma classe transformando todo o tempo de vida das massas em tempo de trabalho" (p. 597).

${ }^{18}$ Marx, K. O Capital I, p. 370.

${ }^{19}$ Laval acrescenta ainda que "Essa ampliação da análise completa o trabalho de Marx mais do que o contradiz. É por isso aliás que, segundo alguns marxistas, a análise foucaultiana é perfeitamente compatível com a ideia 'ortodoxa' segundo a qual as novas formas de poder nas instituições sociais podem ser vistas como efeitos mais ou menos diretos dos processos econômicos. $O$ que fez com que dissessem, por vezes, que havia um 'marxismo escondido' ou um 'marxismo esquecido' de Foucault".p. 35. ${ }^{20}$ Cf. FOUCAULT, 2015a, p. 402.
}

BALBINO, Lorena de Paula. "A guerra civil é a matriz de todas as lutas de poder”: o debate com o marxismo na analítica do poder de Michel Foucault. Griot : Revista de Filosofia, Amargosa-BA, v.18, n.2, p.281-294, dezembro, 2018. 
desenvolvimento do maquinismo e dos novos corpos. Eram corpos om função de multiplicadores de poder, zonas nas quais o poder estava mais concentrado, era mais intenso (FOUCAULT, 2015, p. 189).

Desse modo, fazer a história desses dispositivos disciplinares exige que se vá para além dos muros das fábricas. $O$ capitalismo, nesse sentido, não pode ser a fonte ou a origem única das tecnologias de poder pois, o que Foucault mostra é que elas são difundidas em numerosas instituições que nascem muito antes do progresso da revolução industrial em asilos, hospitais, exércitos, comunidades religiosas, etc.

Essa constatação nos leva a um segundo aspecto da produtividade do poder que, segundo Laval, teria feito Foucault ultrapassar as análises de Marx. Se o capitalismo não é a causa original da extensão das disciplinas na sociedade, ele é condicionado e mesmo constituído por um campo de produção material de tecnologias políticas que são inventados fora dele ${ }^{21}$. Segundo Foucault as disciplinas em funcionamento nas múltiplas instituições produzem o que Foucault chama de "sobre-poder" (sous-pouvoir) ou então de "mais de poder" (plus de pouvoir). O "mais de poder" é o meio pelo qual é possível a separação de uma parte da sociedade, a partir de regras, normas de conduta, sanções judiciárias que ultrapassam a instituição disciplinar. O ponto chave dessa análise é que, segundo Foucault, as disciplinas são a condição da extração da mais-valia. Isso fica mais claro no curso de Foucault de 1973 La verité et les formes juridiques:

\begin{abstract}
Não penso, portanto, que se possa admitir pura e simplesmente a análise tradicionalmente marxista que supõe que, sendo o trabalho a essência concreta do homem, o sistema capitalista é quem transforma esse trabalho em lucro, em sobrelucro ou em mais-valia. Com efeito, o sistema capitalista penetra muito mais profundamente em nossa existência. Tal como foi instaurado no século XIX, esse regime foi obrigado a elaborar um conjunto de técnicas políticas, técnicas de poder, pelo qual o homem se encontra ligado a algo como o trabalho, um conjunto de técnicas pelo qual o corpo e o tempo dos homens se tornam tempo de trabalho e força de trabalho e podem ser efetivamente utilizados para se transformar em sobrelucro. Mas para haver sobre-lucro é preciso haver sub-poder. É preciso que, ao nível mesmo da existência do homem, uma trama de poder político microscópico, capilar, seja estabelecido fixando os homens ao aparelho de produção, fazendo deles agentes da produção, trabalhadores. [...] Não há sobre-lucro sem sub-poder. Falo de subpoder pois se trata do poder que descrevi há pouco e não do que é chamado tradicionalmente de poder político; não se trata de um aparelho de Estado, nem da classe no poder; mas do conjunto de pequenos poderes, de pequenas instituições situadas em um nível mais baixo. $O$ que pretendi fazer foi a análise do sub-poder como condição de possibilidade do sobre-lucro ${ }^{22}$
\end{abstract}

Portanto, o excedente da disciplina é, para Foucault, a condição histórica de um excedente de valor. E, se esse sobre-lucro implica necessariamente um questionamento de um sobre-poder, então uma crítica radical da sociedade deve ser feita sobre novas bases. Isso implica entender que o poder não é apenas o garantidor de um modo de produção. $O$ poder, de fato, funciona dentro de um modo produção, mas, de modo a constituí-lo através de diversas instâncias como, por exemplo, as penitenciárias, as caixas de previdências, etc. $O$ que a análise das instituições de sequestração, dos discursos de moralidade, das disciplinas pretendeu mostrar foi que o poder é algo bem mais difuso. $O$ poder é "algo que passa, se efetua e se exerce" por todo um sistema de conexões e pontos de apoio. Nessa guerra civil que

${ }^{21}$ Cf. Laval, C. 2015, p. 35-36.

${ }^{22}$ FOUCAULT, 2001, p. 1490.

BALBINO, Lorena de Paula. “A guerra civil é a matriz de todas as lutas de poder”: o debate com o marxismo na analítica do poder de Michel Foucault. Griot : Revista de Filosofia, Amargosa-BA, v.18, n.2, p.281-294, dezembro, 2018. 
é o modo pelo qual se exerce o poder o que está no centro são relações belicosas que não obedecem ao esquema monótono da opressão. Isso não quer dizer que não possa haver uma classe social que possa ocupar determinado lugar privilegiado, mas, que o poder não é monolítico. Há sempre pequenas disputas singulares sobre as quais o poder se exerce. Nesse sentido, é indispensável saber reconhecer e fazer a distinção entre o que são sistemas de poder e aparatos estatais.

Toda essa crítica à noção de poder será mais tarde retomada e desenvolvida em Surveiller et punir de modo quase idêntico. Os editores das obras completas de Foucault observam que quando Surveiller et punir foi lançado em fevereiro de 1975 a obra teve um sucesso notável. Isso porque:

\footnotetext{
De um lado ele é imediatamente percebido como uma alternativa ao marxismo e aos seus esquemas de explicação, muitos dos quais não eram suficientes para compreender os acontecimentos da França pós maio de 68. Surveiller et punir transforma o debate sócio-politico, até então marcado por um freudo-marxismo propondo novas conceituações (GROS apud FOUCAULT, 2015a, p. 1462).
}

Deleuze observará o mesmo campo teórico sobre o qual as críticas ao poder de Foucault puderam se desenvolver e se firmar (DELEUZE, 2003, p. 34). Portanto, o modo como a noção de poder é construída e articulada nos trabalhos de Foucault devem muito aos problemas enfrentados pelo marxismo e por todo o conjunto acadêmico da época pós maio de 1968. Nesse sentido, é interessante observar como no curso de 1972 Foucault ainda concebia o poder em termos de repressão, exclusão, ou ainda, de forma negativa, na extração de uma força proveito de outra no interior das batalhas de poder. Já em 1973, Foucault reformula algumas de suas hipóteses anteriores e, através de sua genealogia do proletariado consegue visualizar um poder que, mais do que reprodução, atua no modo de produção, como um superpoder que garante o excesso do capital. 


\section{Referências}

ALTHUSSER, L. Sur la reproduction. Paris: PUF, 1995.

CHIGNOLA, S. Foucault, Marx: le corps, le pouvoir, la guerre. In: LAVAL, C (org). Marx e Foucault: lectures, usages, confrontations. Paris: La découverte, 2015.

DELEUZE, G. Foucault. São Paulo: Brasiliense, 2013.

FOUCAULT, M. Entretien inédit entre Michel Foucault et quatre militants de la LCR, membres de la rubrique culturelle du jornal quotidien Rouge (juillet 1977). Disponível em: http://questionmarx.typepad.fr/files/entretien-avec-michel-foucault-1.pdf

Paris: Gallimard, 2001. Dits et écrits I. (1954-1975) DÉFERT, Daniel.; EWALD, François. (Eds.). . Dits et écrits II. (1976-1988). DÉFERT, Daniel.; EWALD, François. (Eds.). Paris: Gallimard, 2001a. . La Société punitive. Paris: Gallimard, 2013. - A sociedade punitiva. São Paulo: WMF Martins Fontes, 2015. . Euvres completes II. Paris: Gallimard, 2015a.

LAVAL, C. La productivité du pouvoir. In: LAVAL, C (org). Marx e Foucault: lectures, usages, confrontations. Paris: La découverte, 2015.

MARX, K. A ideologia alemã. São Paulo: Boitempo, 2007.

. Manifesto do partido comunista. São Paulo: Boitempo, 2010.

- A guerra civil na França. São Paulo: Boitempo, 2011.

. As lutas de classes na França. São Paulo: Boitempo, 2012.

. O Capital I. São Paulo: Boitempo, 2013.

. Os despossuídos: debates sobre a lei referente ao furto de madeira. São Paulo:

Boitempo, 2017.

THOMPSON, E. A economia moral da multidão inglesa no século XVIII. In: Thompson, Edward. Costumes em comum: estudos sobre a cultura popular tradicional. São Paulo: Companhia das letras, 2010.

Autor(a) para correspondência: Lorena de Paula Balbino, Universidade Federal de São Carlos, Centro de Educação e Ciências Humanas, Rodovia Washington Luis, km 235, CEP 13565-905 São Carlos - SP, Brasil. lorenabalbino_@hotmail.com

BALBINO, Lorena de Paula. "A guerra civil é a matriz de todas as lutas de poder": o debate com o marxismo na analítica do poder de Michel Foucault. Griot : Revista de Filosofia, Amargosa-BA, v.18, n.2, p.281-294, dezembro, 2018. 